\title{
Evaluating Consumer Acceptance of the Commercial Fleet of Methanol Vehicles in China
}

\author{
Chengjiang $\mathrm{Li}^{1,2}$, Michael Negnevitsky ${ }^{3}$, Xiaolin Wang ${ }^{3}$, Honglei Wang ${ }^{1,2}$ and Yujie $\mathrm{Hu}^{1,2 *}$ \\ ${ }^{1}$ School of Management, Guizhou University, Guiyang, China, ${ }^{2}$ Key Laboratory of "Internet+" Collaborative Intelligent \\ Manufacturing in Guizhou Province, Guiyang, China, ${ }^{3}$ School of Engineering, University of Tasmania, Hobart, TAS, Australia
}

OPEN ACCESS

Edited by:

Quande Qin,

Shenzhen University, China

Reviewed by:

Firoz Alam,

RMIT University, Australia

Jingzheng Ren,

Hong Kong Polytechnic University,

Hong Kong SAR, China

*Correspondence:

Yujie Hu

yjhu@gzu.edu.cn

Specialty section:

This article was submitted to Sustainable Energy Systems and

Policies,

a section of the journal Frontiers in Energy Research

Received: 11 October 2021 Accepted: 17 November 2021

Published: 08 December 2021

Citation:

Li C, Negnevitsky $M$, Wang $X$, Wang $H$ and $\mathrm{Hu} Y$ (2021) Evaluating Consumer Acceptance of the Commercial Fleet of

Methanol Vehicles in China.

Front. Energy Res. 9:792982.

doi: 10.3389/fenrg.2021.792982
To enhance domestic energy security and reduce air pollution, China has accelerated the deployment of alternative fuel vehicles including methanol vehicles since the 2010s. Already completed pilot projects have demonstrated that methanol vehicles (commercial fleet) are economical, environmentally friendly, and technically mature. Therefore, the Chinese government aims to continually deploy methanol vehicles in coal-rich provinces. There are more than 20,000 methanol taxis in operation in China, it is important to evaluate the existing consumer acceptance of such commercial fleet before commercialization in a wider range. This paper proposes a conceptual model to identify consumer acceptance of methanol taxis. The model generates hypotheses that have been tested using surveys completed by taxi drivers of methanol vehicles in the cities of Xi'an (Shaanxi province) and Guiyang (Guizhou province). Results demonstrate that market, economic, and technological concerns strongly determine the consumer acceptance of the commercial fleet of methanol vehicles in China.

Keywords: methanol, methanol vehicle, structural equation model, consumer acceptance, China

\section{INTRODUCTION}

With economic growth and the development of the automobile industry, the number of vehicles in China is constantly increasing. However, as the largest automobile market, China faces energy security and environmental challenges (Ji et al., 2019). From an energy security perspective, China imported 507-million-tons of crude oil and 132-billion-cubic meters of natural gas in 2019 to meet its massive energy demand (BP, 2020). From an environmental perspective, over 240 million conventional vehicles using gasoline or diesel contributed more than 36-million-tons of the total vehicle pollutants (Ministry of Ecology and Environment of China, 2019).

To strengthen domestic energy security and protect the atmospheric environment, the Chinese government has issued a series of policies for the development of alternative fuel vehicles (AFVs) (Zhang and Qin, 2018; Li et al., 2019a). Although China has already promoted electric vehicles (EVs) nationwide, other types of AFVs, and such as methanol vehicles, have also been deployed considering the adaption of regional natural resources (Li et al., 2020).

Methanol is mainly produced globally based on coal and natural gas (Hao et al., 2017). Since China's coal production accounts for $47.6 \%$ of the world's total, about $78 \%$ of China's methanol is made from coal through gasification and synthesis processes (BP, 2020). Methanol vehicles refer to vehicles that use pure methanol or blended with gasoline in different proportions based on minor modifications to internal combustion engines (Olah, 2005; Dolan, 2008). Compared with vehicles that use gasoline or diesel, methanol vehicles have fewer exhaust emissions (Wang et al., 2015). Also, 
the low price of methanol fuel and the low cost of "methanolized" conventional vehicles make methanol vehicles competitive from an economic perspective (Su et al., 2013; Li et al., 2020). Therefore, deploying methanol vehicles in coal-rich regions not only reduces energy imports and urban pollution but also achieves socio-economic benefits (Li et al., 2017). Considering that methanol vehicles are particularly competitive in coal-rich regions, their deployment can further diversify the AFV market (Shih et al., 2018; Yao et al., 2018).

In 2012, the Ministry of Industry and Information Technology (MIIT) launched ten pilot projects to comprehensively test the implementation of methanol vehicles (MIIT, 2012). The completed pilot projects demonstrated that methanol vehicles are technically mature, economic, and environmentally friendly (MIIT, 2019). With the success of pilot projects, the Chinese government aims to expand the deployment of methanol vehicles in coal-rich regions (MIIT, 2019). By 2019, more than 20,000 methanol passenger vehicles operate on the road, and all of them are taxi fleets (Li et al., 2020). Before issuing policies to expand the scope of methanol vehicles, it is important to evaluate the current user acceptance of such methanol vehicles from a consumer's perspective. This paper investigates consumer acceptance of the commercial fleet of methanol vehicles and considers policy implications for the further deployment of methanol vehicles in China. The rest of this paper is structured as follows: Review of Consumer Acceptance Models reviews consumer acceptance models; Proposed Conceptual Model and Hypotheses demonstrates the proposed conceptual model and hypotheses; Methodology details methodology for testing hypotheses; Results and Discussion provides results and discussion; the last section is conclusions and policy implications.

\section{REVIEW OF CONSUMER ACCEPTANCE MODELS}

As an AFV that has not been commercialized in China, methanol vehicles are regarded as new technology from the consumer's perspective. The Technology Acceptance Model (TAM) was developed to explore the public acceptance of new technologies (Davis, 1989). TAM explains how perceived usefulness (relative advantage) and ease of use subsequently influence adoption decisions and personal behavioral intentions (Davis, 1989; Petschnig et al., 2014; Wu et al., 2019). Based on TAM, TAM2 is proposed, which includes more constructs such as social influence processes (subjective norm, voluntariness, and image) and cognitive instrumental processes (job relevance, output quality, and result demonstrability) (Venkatesh and Davis, 2000). Both TAM and TAM2 have been widely applied to assess the acceptance of various new technologies, including AFVs (Dudenhöffer, 2013; Pfoser et al., 2018; Wu et al., 2019). In addition, Venkatesh and Bala (2008) introduced new constructs such as computer self-efficacy and computer anxiety, and thereby improving TAM2 (Lai, 2017). As another theoretic framework for analyzing user behavior and acceptance, TAM3 was developed (Hameed et al.,
2012; Chen, 2018). Although TAM3 has been mainly applied in IT implementation, its constructs, and such as objective usability and perception of external control, and were also introduced to evaluate the acceptance of AFVs (Globisch et al., 2018).

Although TAM and its extended models are useful, numerous efforts have been made to improve their explanatory power. The Unified Theory of Acceptance and Use of Technology (UTAUT) was developed as an integrated model to enhance the understanding of technology adoption based on traditional TAM models (Venkatesh et al., 2003). Its constructs, including facilitation conditions, efforts expectancy, performance expectancy, and social influence, enable UTAUT to directly address the intent to use technology (Sovacool, 2017). To improve the original UTAUT, UTAUT2 which includes additional variables such as hedonic motivation, price value, and habit was formulated (Venkatesh et al., 2012). In addition to mobile and computer technology industries, UTAUT and its extended models have also been used to examine the adoption of AFVs (Khazaei and Khazaei, 2016; Sovacool, 2017). The constructs of TAM and its extended models including TAM2, TAM3, UTAUT, and UTAUT2 are illustrated in Figure 1.

The Theory of Planned Behavior (TPB) has been developed to predict the user's intentions. According to TPB, this intention is determined by constructs including attitude toward behavior, subjective norm, and perceived behavior control to predict the intention of various behaviors (Ajzen, 1991; Leonard et al., 2004). As an effective model for explaining behavioral intention, TPB has been used to analyze AFV's acceptance and purchase intentions (Mohamed et al., 2016; Afroz et al., 2015; Barbarossa et al., 2015; Wang et al., 2018; Xu et al., 2019). By comparing TAM and TPB in predicting the user's intention, Mathieson (1991) concluded that both theories are appropriate. The former model is easy to implement, while the latter can capture most aspects of an individual's belief through more variables (Chuttur, 2009).

Although TPB and TAM-related models are indeed popular when predicting the acceptance of new technology, they have limitations in terms of construct consideration. According to Will and Schuller (2016), it is difficult to develop conceptual models solely based on TPB or TAM-related models since consumers maybe lack hands-on experience in operating AFVs. Therefore, apart from existing normative variables, domain-specific constructs such as environmental or economic factors that also influence an individual intention should be considered (Burton-Jones and Hubona, 2006; Donald et al., 2014). To increase the comprehensiveness, many studies regarding AEV acceptance improved the original TAM or TPB models by introducing new constructs such as environmental concern (Barbarossa et al., 2015; Mohamed et al., 2016; Wu et al., 2019) and policy support (Zhang et al., 2018; Xu et al., 2019). In addition, other conceptual models which are independent of TPB or TAM-related models have been proposed for assessing the acceptance of AFVs (Kang and Park, 2011; Lai et al., 2015; Degirmenci and Breitner, 2017; Han et al., 2017; She et al., 2017; 


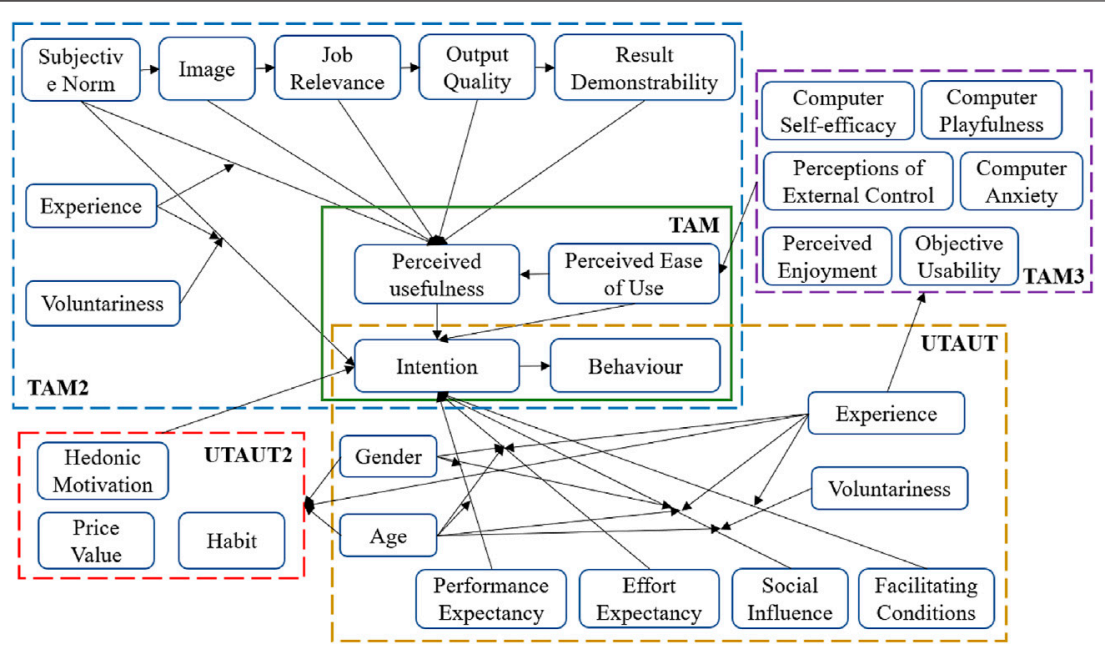

FIGURE 1 | Technology acceptance model-based models and their constructs.

TABLE 1 | Constructs and models used for investigating AFV's acceptance.

Reference

Wu et al. (2019)

Xu et al. (2019)

Globisch et al. (2018)

Park et al. (2018)

Pfoser et al. (2018)

Wang et al. (2018)

Zhang et al. (2018)

Degirmenci \& Breitner (2017)

Han et al. (2017)

She et al. (2017)

Khazaei \& Khazaei (2016)

Mohamed et al. (2016)

Wang et al. (2016)

Will \& Schuller (2016)

Afroz et al. (2015)

Barbarossa et al. (2015)

Penerbit (2015)

Zhou et al. (2015)

Lai et al. (2015)

Petschnig et al. (2014)

Dudenhöffer (2013)

Kang \& Park (2011)

\section{Type}

Green perceived usefulness, environmental concern, behavior intention, and perceived ease of use

BEV Attitude, perceived behavioral control, subject norm, environmental performance, price value, and incentive policy

EVs Subjective norms, image and tasks, objective usability, perceived usefulness, ease of use, external control, and involvement

EVs Perceived usefulness, ease of use and enjoyment, satisfaction, public attitude, and perceived cost

GVs Accessibility, attitude, safety, usability, and usefulness

EVs Technical level, performance, cost of ownership, charging services, marketing, perceived values and risks, and innovative personality

EVs Policy support, attitude, subjective norm, and perceived behavioral control

EVs Environmental performance, price value, range confidence, and attitude

EVs Emotional value, social value, epistemic value, monetary value, performance value, convenience value, functional value, and attitude

EVs Vehicle performance barrier, infrastructure barrier, and the financial barrier

EVs Social influence, facilitating conditions, the anxiety of use, perceived enjoyment, and environmental concern

EVs Environmental concern, attitude, subjective norm, perceived behavioral control, and personal moral norm

HEV Environmental concern, attitude, subjective norm, perceived behavioral control, and personal moral norm

EVs Monetary incentives, system effects, user-friendliness, data security, and the general attitude

EVs Perceived behavioral control, subjective norms, attitudes, purchase intention, individual and environmental consequences

EVs Green self-identity, environmental consequences of using cars, green moral obligation, and attitude

NGV Refueling station availability, initial modification cost, petrol price, and refueling time for NGV

EVs Technological readiness, market readiness, institutional readiness, testing and showing,

EVs Environmental concern, perception of environmental policy and EVs, and reception of economic benefit

AFVs Perceived innovation characteristics, personal norm, attitude formation, and subjective norm

EVs Perceived ease of use, usefulness, subjective norm, affect, objective usability, experience, and price sensitivity

FCEV Acceptance, psychological needs, perceptions, and values, experiences
Model

TAM

TPB

TAM3

TAM

TAM

Independent

TPB

Independent

Independent

Independent

UTAUT2

TPB

TPB

Independent

TPB

TPB

Independent

Independent

Independent

TPB

TAM

Independent
Wang et al., 2018). Previous studies regarding AFVs acceptance using TPB, TAM-related, or independent conceptual models are summarized as shown in Table 1.

As can be seen from Table 1, previous studies engaged different constructs to develop models for assessing the acceptance or purchase intention of AFVs. However, no study exists to date which is explicitly dedicated to the acceptance of methanol vehicles. Therefore, to address this gap, this paper proposed a conceptual model to investigate methanol vehicle's acceptance in China. 


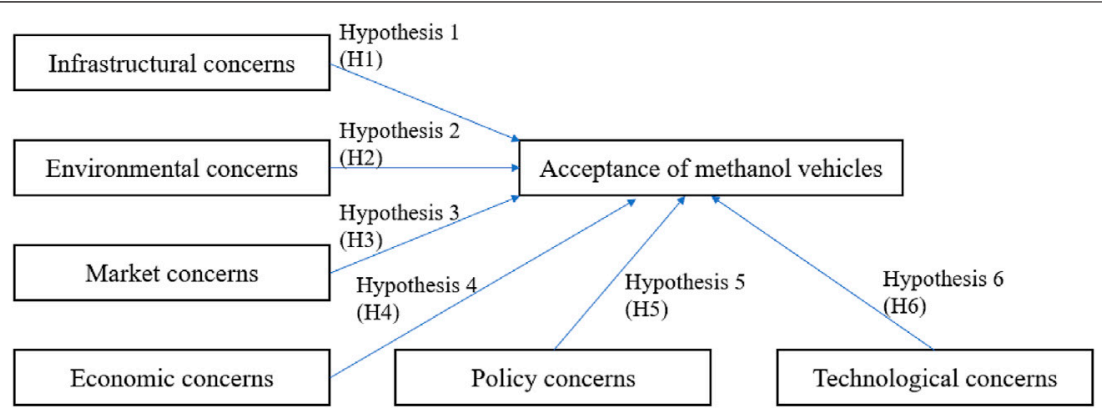

FIGURE 2 | The proposed conceptual model for assessing methanol vehicle acceptance in China.

\section{PROPOSED CONCEPTUAL MODEL AND HYPOTHESES}

The proposed conceptual model is developed to investigate the acceptance of methanol vehicles in China (Figure 2). This model includes the following constructs: environmental, economic, technological, market, infrastructural, and policy concerns. It not only considers constructs from the TPB and TAM-related models (i.e., environmental concerns) but also includes construct from independent models that may affect consumer acceptance of methanol vehicles (i.e., market concerns). The purpose of enhancing the original models is to provide policy implications for further adoption of methanol vehicles in China. The rest of this section explains the selection of constructs for the development of hypotheses.

Provision of sufficient infrastructure such as refueling stations or charging services directly affects consumer acceptance of AFVs. Facilitating conditions and services were considered when developing models for evaluating the adoption of EVs (Khazaei and Khazaei, 2016; She et al., 2017; Wang et al., 2018). Also, the availability of refueling stations was included as the main construct in the models for testing an individual's intention to use gas vehicles (Penerbit 2015; Pfoser et al., 2018). As the number of methanol vehicles increases in pilot cities, the distribution of refueling stations will influence the adoption of methanol vehicles (Li et al., 2019b). Therefore, the first hypothesis of this study is proposed from the perspective of infrastructure:

Hypothesis 1 Infrastructural concerns positively determine consumer acceptance of methanol vehicles.

Due to the serve pollution caused by conventional vehicles, Chinese people's awareness of environmental protection is increasing ( $\mathrm{Xu}$, et al., 2019). Therefore, the environmental concern is directly relevant to the acceptance of AFVs by the consumer (Wu et al., 2019). Previous studies have shown that environmental awareness is important in terms of the willingness to purchase EVs (Barbarossa et al., 2015; Lai et al., 2015; Wang et al., 2016). Considering that the main purpose of promoting methanol vehicles is to reduce air pollution, environmental performance should be included as a construct when determining consumer acceptance of methanol vehicles. Therefore, the second hypothesis is proposed from the environmental point of view:

Hypothesis 2 Environmental concerns positively determine consumer acceptance of methanol vehicles.

Market concerns are related to the participation of methanol vehicle manufacturers in the vehicle market. One of the main goals of deploying methanol vehicles in China is to reduce its dependence on oil and diversify the AFV market (Li et al., 2020). Previous studies included market-related constructs when assessing the acceptance of EVs (Zhou et al., 2015; Wang et al., 2018). Considering that methanol vehicles may become an important type of AFV in coal-rich provinces, it is necessary to evaluate consumer's concerns about the methanol vehicle market. Therefore, the third hypothesis is proposed from the market perspective.

Hypothesis 3 Market concerns positively determine consumer acceptance of methanol vehicles.

When assessing consumer acceptance of AFVs, constructs related to economic concerns were commonly included in previous theoretical models. Specifically, price value was regarded as a construct in TPB-based models to identify the user's intention to purchase EVs (Degirmenci and Breitner, 2017; $\mathrm{Xu}$ et al., 2019). Similarly, cost-related constructs such as perceived cost and price sensitivity were included in TAM or independent models to understand the public attitudes towards different types of AFVs (Kang and Park, 2011; Dudenhöffer, 2013; Penerbit 2015; Park et al., 2018). Because methanol vehicles have price advantages in both vehicle and fuel, consumer's economic concerns will affect the acceptance of methanol vehicles. Therefore, the fourth hypothesis is developed from an economic perspective:

Hypothesis 4 Economic concerns positively determine consumer acceptance of methanol vehicles.

Because policy support plays an important role in accelerating the deployment of AFVs in China, previous studies included this construct when establishing theoretical models. For example, policy incentives and 
policy support were selected as key constructs affecting the adoption of EVs (Langbroek et al., 2016; Zhang et al., 2018; $\mathrm{Xu}$ et al., 2019). Although there are currently not enough financial incentives to develop methanol vehicles in China, other policy support such as no license plate restriction will determine consumer's intentions to use methanol vehicles ( $\mathrm{Li}$ et al., 2019b). Therefore, the fifth hypothesis is proposed from the perspective of policy:

Hypothesis 5 Policy concerns positively determine consumer acceptance of methanol vehicles.

As the basic construct of TAM and its extended models, technology-related constructs such as usability, usefulness, and accessibility were often selected in previous studies investigating AFVs acceptance (Dudenhöffer, 2013; Globsich et al., 2018; Wu et al., 2019). Other technology-related constructs (such as technical level and readiness) were also included in the independent models used to test the adoption of EVs (Zhou et al., 2015; Wang et al., 2018). Although the pilot projects demonstrated that methanol vehicles are technically mature, consumer's technological concerns, including driving range and the safety of using methanol as fuel, and still need to be considered. Therefore, the last hypothesis is proposed from a technical perspective:

Hypothesis 6 Technological concerns positively determine consumer acceptance of methanol vehicles.

\section{METHODOLOGY}

\section{Survey Design: Study Area, Sample, and Data Collection}

A questionnaire survey method was applied to test the proposed hypotheses. The survey was conducted in Xi'an (the capital city of Shaanxi province) and Guiyang (the capital city of Guizhou province) from June to July 2020. Xi'an and Guiyang were selected for the following reasons: 1) Xi'an and Guiyang are two major methanol vehicle pilot cities, with the greatest number of methanol vehicles and methanol refueling stations in operation. Each city has approximately 10,000 methanol taxis which is far more than other pilot cities. 2) Both Xi'an and Guiyang municipal governments implement a list of policies to deploy methanol vehicles and planned to commercialize methanol vehicles in 2021 ( $\mathrm{Li}$ et al., 2019a). 3) Both cities also deploy gas and electric vehicles, which diversifies their AFVs market. Therefore, the respondents in Xi'an and Guiyang could have a comprehensive and objective idea when evaluating methanol vehicles.

Considering that our research objective is to examine methanol vehicle's acceptance, it is necessary to include the respondents who have already used methanol vehicles. The total number of methanol passenger vehicles has already exceeded 20,000 in China. However, all of them are used as taxis. Therefore, taxi drivers of methanol vehicles from Xi'an and Guiyang were selected as respondents.

A small study with 50 responses was conducted to verify the validity of the questionnaire. After this study, the questionnaire was modified accordingly, and 600 finalized questionnaires were distributed to two target groups of respondents through online surveys. Specifically, 300 questionnaires were distributed to taxi drivers of methanol vehicles in Xi'an, and the rest were given out to taxi drivers in Guiyang.

\section{Procedure and Measures}

The questionnaire designed based on the proposed conceptual model includes three sections (Supplementary Table SA1). The first section explains the research aim and the guidelines of the questionnaire. The second section includes the sociodemographic information of the respondents. The third section demonstrates the measurement for scale items of conceptual model constructs. The construction of the scale items is based on TPB and TAM-related models using the scale development procedures suggested in (Sweeney and Soutar, 2001; Rossiter, 2002).

In total, 23 measurement items were applied to measure seven constructs including six different aspects and methanol vehicle acceptance. The respondents were invited to indicate their level of agreement for the items based on a 7-Likert scale ranging from 1 to 7 , where 1 represents strong disagreement and 7 represents strong agreement (Barbarossa et al., 2015; Wu et al., 2019).

\section{Structural Equation Model}

The structural equation model (SEM) is developed to analyze the relationships among unobserved constructs (latent variables) from observed indicators (She et al., 2017). In general, SEM contains two sub-models: a measurement model that describes the relationships of constructs (latent variables) and their corresponding observed variables; a structural model that illustrates the causal relationship among the constructs (Bollen et al., 2014; Zhang et al., 2018). SEM is a technique for reducing errors when measuring subjective latent constructs and incorporating them into hypothesis testing (Hair et al., 2010; Mohamed et al., 2016). Therefore, SEM has been widely used in social science including the examination of AFVs acceptance (Han et al., 2017; Wu et al., 2019; Xu et al., 2019). Since methanol vehicles have not yet found wide application in China, many features of consumer acceptance of methanol vehicles cannot be described directly. Because SEM represents a tool for testing the relationship between variables, it is used for assessing the acceptance of methanol vehicles in China. Partial Least Squares (PLS) is selected to estimate the parameters of SEM. According to Degirmenci and Breitner (2017), the PLS approach requires a relatively small size of samples and is appropriate for the early stages of research such as the adoption of methanol vehicles. Based on the formula for sample size calculation (Afroz et al., 2015), the number of valid questionnaires in this study is acceptable for the application of structural equation modeling. 


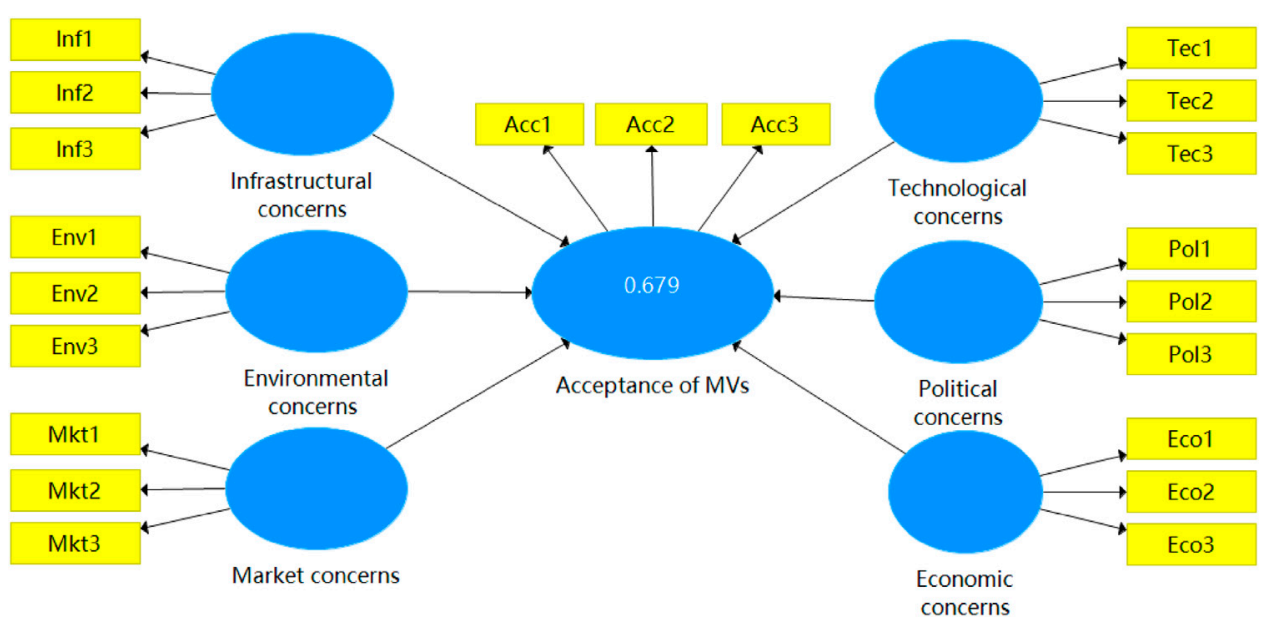

FIGURE 3 | The proposed structural equation model of methanol vehicles acceptance.

TABLE 2 | Results of the measurement model.

\begin{tabular}{|c|c|c|c|c|c|}
\hline Construct & Items & Loading & Cronbach's a & $\begin{array}{c}\text { Composite reliability } \\
\text { (CR) }\end{array}$ & $\begin{array}{c}\text { Average variance } \\
\text { extracted (AVE) }\end{array}$ \\
\hline \multirow[t]{3}{*}{ Infrastructural concerns } & $\operatorname{lnf1}$ & 0.770 & 0.613 & 0.753 & 0.507 \\
\hline & $\operatorname{lnf} 2$ & 0.614 & & & \\
\hline & Inf3 & 0.742 & & & \\
\hline \multirow[t]{3}{*}{ Environmental concerns } & Env1 & 0.896 & 0.667 & 0.803 & 0.581 \\
\hline & Env2 & 0.691 & & & \\
\hline & Env3 & 0.679 & & & \\
\hline \multirow[t]{3}{*}{ Market concerns } & Mkt1 & 0.899 & 0.880 & 0.926 & 0.806 \\
\hline & Mkt2 & 0.924 & & & \\
\hline & Mkt3 & 0.871 & & & \\
\hline \multirow[t]{3}{*}{ Economic concerns } & Eco1 & 0.887 & 0.738 & 0.851 & 0.657 \\
\hline & Eco2 & 0.847 & & & \\
\hline & Eco3 & 0.684 & & & \\
\hline \multirow[t]{3}{*}{ Policy concerns } & Pol1 & 0.842 & 0.684 & 0.824 & 0.611 \\
\hline & Pol2 & 0.810 & & & \\
\hline & Pol3 & 0.683 & & & \\
\hline \multirow[t]{3}{*}{ Technological concerns } & Tec1 & 0.870 & 0.832 & 0.898 & 0.748 \\
\hline & Tec2 & 0.871 & & & \\
\hline & Tec3 & 0.855 & & & \\
\hline \multirow[t]{3}{*}{ Acceptance } & Acc1 & 0.821 & 0.833 & 0.899 & 0.749 \\
\hline & Acc2 & 0.893 & & & \\
\hline & Acc3 & 0.881 & & & \\
\hline
\end{tabular}

\section{RESULTS AND DISCUSSION}

A total number of 354 validated questionnaires have been collected, based on the statistics provided by an online survey machine. The collected data is used as the input to the proposed SEM model (Figure 3). The results are obtained using the PLS algorithm.

According to the value of determination coefficient $R^{2}$ shown in Figure 3, the examined constructs explained a total of $67.9 \%$ of the variance, indicating that the proposed model is a well-fitted regression model (Kristal et al., 2010). Table 2 shows the measurement results, including loading, Cronbach's $\alpha$, composite reliability, and average variance extracted values.
The loading of each item is deemed to be acceptable because its value exceeds the threshold of 0.6 (Anderson and Gerbing, 1988; Han et al., 2017; Pfoser et al., 2018). Similarly, Cronbach's a for infrastructural, environmental and policy concerns are acceptable $(>0.6)$. The values of the remaining constructs are excellent (>0.7). The results of composite reliability $(>0.7)$ and average variance extracted $(>0.5)$ also meet the recommended thresholds (Anderson and Gerbing, 1988; Han et al., 2017; Pfoser et al., 2018). In order to test the validity of data collection, the discriminant validity is calculated (Table 3).

It can be seen from Table 3 that the values on the diagonal are the largest in each column. Therefore, the results also demonstrate the validity of data collection. The proposed 
TABLE 3 | Discriminant Validity.

\begin{tabular}{|c|c|c|c|c|c|c|c|}
\hline & Acceptance & $\begin{array}{l}\text { Economic } \\
\text { concerns }\end{array}$ & $\begin{array}{c}\text { Environmental } \\
\text { concerns }\end{array}$ & $\begin{array}{c}\text { Market } \\
\text { concerns }\end{array}$ & $\begin{array}{l}\text { Infrastructural } \\
\text { concerns }\end{array}$ & $\begin{array}{c}\text { Policy } \\
\text { concerns }\end{array}$ & $\begin{array}{c}\text { Technological } \\
\text { concerns }\end{array}$ \\
\hline Acceptance & 0.866 & & & & & & \\
\hline Economic concerns & 0.721 & 0.811 & & & & & \\
\hline $\begin{array}{l}\text { Environmental } \\
\text { concerns }\end{array}$ & 0.630 & 0.591 & 0.762 & & & & \\
\hline Market concerns & 0.756 & 0.678 & 0.716 & 0.898 & & & \\
\hline $\begin{array}{l}\text { Infrastructural } \\
\text { concerns }\end{array}$ & 0.486 & 0.492 & 0.422 & 0.555 & 0.712 & & \\
\hline Policy concerns & 0.483 & 0.361 & 0.595 & 0.537 & 0.287 & 0.781 & \\
\hline $\begin{array}{l}\text { Technological } \\
\text { concerns }\end{array}$ & 0.749 & 0.740 & 0.631 & 0.761 & 0.563 & 0.547 & 0.865 \\
\hline
\end{tabular}

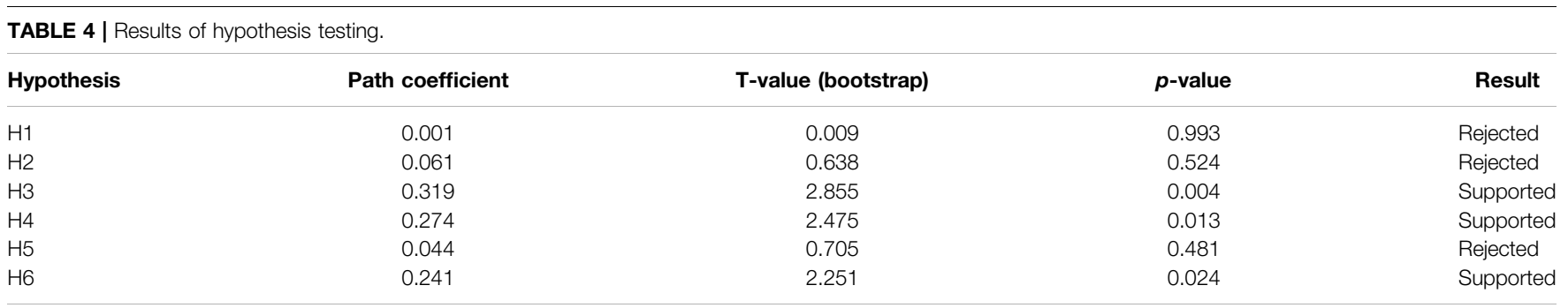

TABLE 5 | Group comparison of hypothesis testing.

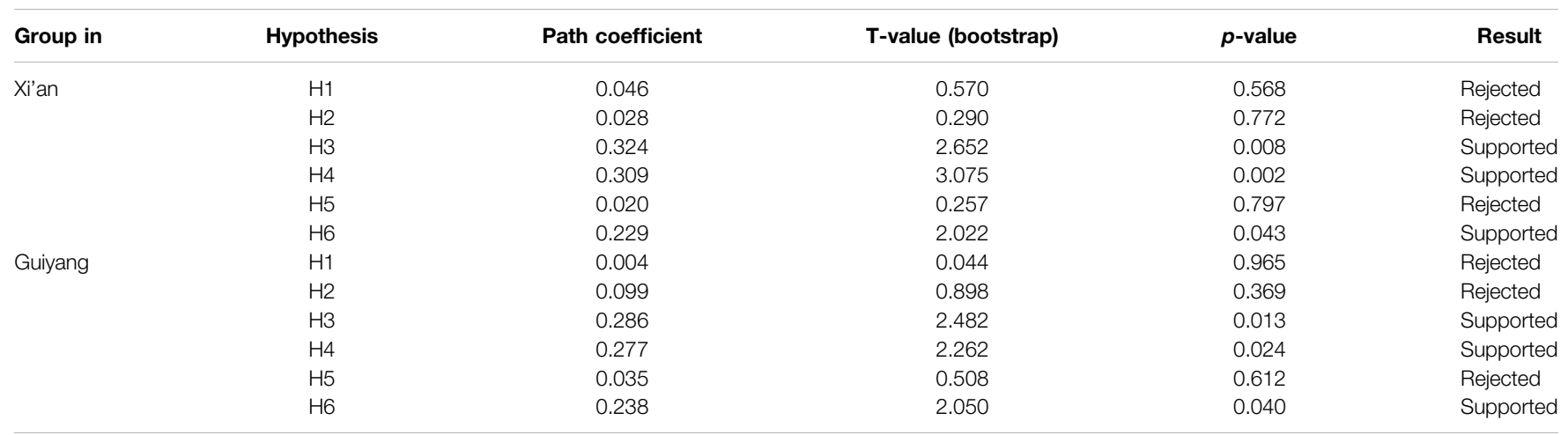

conceptual model is in line with the acceptable levels of reliability and is well-supported by the collected data.

The results of hypothesis testing with all data input are presented in Table 4. According to previous studies, $p$-value has been widely used to test hypotheses (Pfoser et al., 2018; She et al., 2017). Based on $p$-value ( $>0.05$ ), hypotheses 1,2 , and 5 are rejected, which means that infrastructural, environmental, and policy concerns have a negligible impact on the acceptance of methanol vehicles. In contrast, hypotheses 3, 4, and 6 are supported, meaning that market, economic, and technological concerns strongly determine the consumer acceptance of methanol vehicles. Specifically, the path coefficient of market concerns is the highest, indicating that market-related items have the greatest impact on the consumer acceptance of the commercial fleet of methanol vehicles in China. Due to the lack of participation of manufacturers and the current immature methanol vehicle industry chain, this result is quite reasonable. Moreover, economic and technological concerns which also have high path coefficient values, greatly influence the adoption of methanol vehicles. Considering that all 
respondents were taxi drivers, it was reasonable to expect that they gave priority to items related to economic and technical perspectives, and such as fuel price and driving range.

Since the survey was conducted in two cities, this study used different data to compare the acceptance of methanol vehicles between two groups of taxi drivers (Table 5).

According to the results shown in Table 5, consumers (taxi drivers) in two cities had a very similar rate of acceptance of methanol vehicles. Consumers in both Xi'an and Guiyang are more concerned about items of market, economic, and technological aspects than that of environmental, infrastructural, and policy aspects. However, there are some minor differences based on the comparison of $p$-values. Specifically, economic concerns have a much greater impact on taxi drivers of methanol vehicles in Xi'an (0.002) than that of Guiyang (0.024). Since the diversification of the AFV market in Xi'an (gas vehicles), the price advantage of methanol fuel in Xi'an is not as good as in Guiyang. Also, based on the comparison of $p$-values for hypothesis 1 , taxi drivers in $\mathrm{Xi}^{\prime}$ an have more concerns from an infrastructural perspective than drivers in Guiyang. This is because the city of Xi'an is larger than Guiyang, but the density of refueling stations is lower. In general, there is no significant difference in terms of the acceptance of methanol vehicles between the two cities.

\section{CONCLUSION AND POLICY IMPLICATIONS}

Evaluating consumer acceptance of the commercial fleet of methanol vehicles is essential for the further deployment of methanol vehicles in China. By interviewing consumers (taxi drivers of methanol vehicles), the appropriate constructs that may affect the adoption of methanol vehicles were investigated. According to the results of the proposed structural equation model, market, economic, and technological concerns greatly determine the acceptance of methanol vehicles. However, the impacts of environmental, infrastructural, and policy factors are not so obvious. This paper compares data from two different cities currently leading the deployment of methanol vehicles. The results also demonstrate that taxi drivers in $\mathrm{Xi}^{\prime}$ an are more concerned with economic and infrastructural items than drivers in Guiyang. Although the results are limited and based on interviewing taxi drivers because they are currently representing the only drivers of methanol passenger vehicles, we can draw the following policy implications for decisionmakers in the central and provincial governments to formulate policies for further deploying methanol vehicles in China:

- The impact of infrastructural concerns on the acceptance of methanol vehicles is relatively small, indicating that the current construction and layout of refueling stations in Xi'an and Guiyang are acceptable. However, with the commercialization of methanol vehicles, consumer's concerns about the quality and quantity of refueling stations will increase. Therefore, the central government needs to strengthen and standardize infrastructure construction to ensure the smooth operation of methanol vehicles in the whole country.

- From an economic perspective, considering that the promotion of the commercial fleet largely relies on financial support, and it is recommended that the provincial and local governments continue to provide subsidies for methanol fuel and vehicles. In regions where the deployment of methanol vehicles is prioritized, it is important to emphasize the price advantages of both methanol fuel and methanol vehicles.

- From a market perspective, as only a few automakers are making methanol commercial fleet, and the government should encourage automakers to participate in the manufacture of methanol vehicles. As more and more automakers enter the market of methanol vehicles, consumers will have a choice in selecting an appropriate model of methanol vehicles.

- From a technical point of view, the government should further improve the technical standards of both methanol fuel and methanol vehicles and strengthen the research and development of methanol vehicles. Although the current respondents are satisfied with the safety and reliability of methanol vehicles, more data need to be collected to assess whether there are technical problems in operation.

\section{DATA AVAILABILITY STATEMENT}

The raw data supporting the conclusion of this article will be made available by the authors, without undue reservation.

\section{ETHICS STATEMENT}

The studies involving human participants were reviewed and approved by the University of Tasmania. The patients/ participants provided their written informed consent to participate in this study. Written informed consent was obtained from the individual(s) for the publication of any potentially identifiable images or data included in this article.

\section{AUTHOR CONTRIBUTIONS}

Conceptualization, $\mathrm{MN}, \mathrm{XW}$, and $\mathrm{CL}$; writing-original draft preparation, CL; writing-review and editing, $\mathrm{YH}$ and HW. All authors have read and agreed to the published version of the manuscript.

\section{FUNDING}

This Work was Supported by the Humanities and Social Science Research Youth Fund project of Ministry of Education (Grant numbers 21YJC630041). 


\section{ACKNOWLEDGMENTS}

The authors would like to acknowledge Mr. Michael van Baarle (ABEL Energy, Australia), Mr. Guangyuan He (Former Minister of China Ministry of Machine Building, Leader of National Methanol Vehicles Leading Group), Mr. Zhigui Peng (Former Vice Governor of Shanxi Province, Leader of Shanxi Methanol Vehicles), Mr. Jiajun Ma, Mrs. Lei Shi (Directors of Shanxi Provincial Governments), and Mr. Liang Wang (Zhejiang

\section{REFERENCES}

Afroz, R., Masud, M. M., Akhtar, R., Islam, M. A., and Duasa, J. B. (2015). Consumer purchase Intention towards Environmentally Friendly Vehicles: an Empirical Investigation in Kuala Lumpur, Malaysia. Environ. Sci. Pollut. Res. 22 (20), 16153-16163. doi:10.1007/s11356-015-4841-8

Ajzen, I. (1991). The Theory of Planned Behavior. Organizational Behav. Hum. Decis. Process. 50 (2), 179-211. doi:10.1016/0749-5978(91)90020-t

Anderson, J. C., and Gerbing, D. W. (1988). Structural Equation Modeling in Practice: A Review and Recommended Two-step Approach. Psychol. Bull. 103 (3), 411-423. doi:10.1037/0033-2909.103.3.411

Barbarossa, C., Beckmann, S. C., De Pelsmacker, P., Moons, I., and Gwozdz, W. (2015). A Self-Identity Based Model of Electric Car Adoption Intention: a Cross-Cultural Comparative Study. J. Environ. Psychol. 42, 149-160. doi:10.1016/j.jenvp.2015.04.001

Bollen, K. A., Harden, J. J., Ray, S., and Zavisca, J. (2014). BIC and Alternative Bayesian Information Criteria in the Selection of Structural Equation Models. Struct. equation Model. a multidisciplinary J. 21 (1), 1-19. doi:10.1080/ 10705511.2014.856691

BP (2020). Statistical Review of World Energy $69^{\text {th }}$ Edition. Available at: https:// www.bp.com/content/dam/bp/business-sites/en/global/corporate/pdfs/energyeconomics/statistical-review/bp-stats-review-2020-full-report.pdf (Accessed Jul 20, 2020).

Burton-Jones, A., and Hubona, G. S. (2006). The Mediation of External Variables in the Technology Acceptance Model. Inf. Manag. 43 (6), 706-717. doi:10.1016/ j.im.2006.03.007

Chen, J. K. (2018). The Influence of Behavioural Intention on Third-Party E-Commerce Payment. Sajems 21 (1), 1-9. doi:10.4102/sajems.v21i1.2157

Chuttur, M. Y. (2009). Overview of the Technology Acceptance Model: Origins, Developments and Future Directions. Working Pap. Inf. Syst. 9 (37), 9-37. Available at: http://sprouts.aisnet.org/9-37.

Davis, F. D. (1989). Perceived Usefulness, Perceived Ease of Use, and User Acceptance of Information Technology. MIS Q. 13, 319-340. doi:10.2307/ 249008

Degirmenci, K., and Breitner, M. H. (2017). Consumer purchase Intentions for Electric Vehicles: Is green More Important Than price and Range? Transportation Res. D: Transport Environ. 51, 250-260. doi:10.1016/j.trd.2017.01.001

Dolan, G. (2008). China Takes Gold in Methanol Fuel. J. Energ. Security. Available at: http://www.ensec.org/index.php?option $=$ com_content\&view=article\&id $=148$ : chinatakesgoldinmethanolfuel\&catid=82:asia\&Itemid=324 (Accessed July 25, 2020).

Donald, I. J., Cooper, S. R., and Conchie, S. M. (2014). An Extended Theory of Planned Behaviour Model of the Psychological Factors Affecting Commuters' Transport Mode Use. J. Environ. Psychol. 40, 39-48. doi:10.1016/j.jenvp.2014.03.003

Dudenhöffer, K. (2013). Why Electric Vehicles Failed. J. Manag. Control. 24 (2), 95-124. doi:10.1007/s00187-013-0174-2

Globisch, J., Dütschke, E., and Schleich, J. (2018). Acceptance of Electric Passenger Cars in Commercial Fleets. Transportation Res. A: Pol. Pract. 116, 122-129. doi:10.1016/j.tra.2018.06.004

Hair, J. F., Black, W. C., Babin, B. J., and Anderson, R. E. (2010). Multivariate Data Analysis. Global edition. Upper Saddle River: Pearson Higher Education.

Hameed, M. A., Counsell, S., and Swift, S. (2012). A Conceptual Model for the Process of IT Innovation Adoption in Organizations. J. Eng. Tech. Manag. 29 (3), 358-390. doi:10.1016/j.jengtecman.2012.03.007
Geely Holding Group), all participants who made efforts for this project.

\section{SUPPLEMENTARY MATERIAL}

The Supplementary Material for this article can be found online at: https://www.frontiersin.org/articles/10.3389/fenrg.2021.792982/ full\#supplementary-material

Han, L., Wang, S., Zhao, D., and Li, J. (2017). The Intention to Adopt Electric Vehicles: Driven by Functional and Non-functional Values. Transportation Res. Part A: Pol. Pract. 103, 185-197. doi:10.1016/j.tra.2017.05.033

Hao, H., Liu, Z., Zhao, F., Du, J., and Chen, Y. (2017). Coal-derived Alternative Fuels for Vehicle Use in China: a Review. J. Clean. Prod. 141, 774-790. doi:10.1016/j.jclepro.2016.09.137

Ji, Q., Zhang, H.-Y., and Zhang, D. (2019). The Impact of OPEC on East Asian Oil Import Security: A Multidimensional Analysis. Energy Policy 126, 99-107. doi:10.1016/j.enpol.2018.11.019

Kang, M. J., and Park, H. (2011). Impact of Experience on Government Policy toward Acceptance of Hydrogen Fuel Cell Vehicles in Korea. Energy policy 39 (6), 3465-3475. doi:10.1016/j.enpol.2011.03.045

Khazaei, H., and Khazaei, A. (2016). Electric Vehicles and Factors that Influencing Their Adoption Moderating Effects of Driving Experience and Voluntariness of Use (Conceptual Framework). J. Business Manag. 18 (12), 60-65. doi:10.9790/ 487X-1812036065

Kristal, M. M., Huang, X., and Roth, A. V. (2010). The Effect of an Ambidextrous Supply Chain Strategy on Combinative Competitive Capabilities and Business Performance. J. Operations Manag. 28 (5), 415-429. doi:10.1016/ j.jom.2009.12.002

Lai, I., Liu, Y., Sun, X., Zhang, H., and Xu, W. (2015). Factors Influencing the Behavioural Intention towards Full Electric Vehicles: An Empirical Study in Macau. Sustainability 7 (9), 12564-12585. doi:10.3390/su70912564

Lai, P. (2017). The Literature Review of Technology Adoption Models and Theories for the novelty Technology. Jistem 14 (1), 21-38. doi:10.4301/ s1807-17752017000100002

Langbroek, J. H. M., Franklin, J. P., and Susilo, Y. O. (2016). The Effect of Policy Incentives on Electric Vehicle Adoption. Energy Policy 94, 94-103. doi:10.1016/ j.enpol.2016.03.050

Leonard, L. N. K., Cronan, T. P., and Kreie, J. (2004). What Influences IT Ethical Behavior Intentions-Planned Behavior, Reasoned Action, Perceived Importance, or Individual Characteristics? Inf. Manag. 42 (1), 143-158. doi:10.1016/j.im.2003.12.008

Li, C., Negnevitsky, M., and Wang, X. (2020). Prospective Assessment of Methanol Vehicles in China Using FANP-SWOT Analysis. Transport Policy 96, 60-75. doi:10.1016/j.tranpol.2020.06.010

Li, C., Negnevitsky, M., and Wang, X. (2019b). Review of Methanol Vehicle Policies in China: Current Status and Future Implications. Energ. Proced. 160, 324-331. doi:10.1016/j.egypro.2019.02.164

Li, C., Negnevitsky, M., Wang, X., Yue, W. L., and Zou, X. (2019a). Multi-criteria Analysis of Policies for Implementing Clean Energy Vehicles in China. Energy Policy 129, 826-840. doi:10.1016/j.enpol.2019.03.002

Li, C., Yue, W., and Zou, X. (2017). Study on the Optimal Subsidy Policy for the Development of Methanol Vehicle in China. Proc. East. Asia Soc. Transportation Stud. 11. 2017. Available at: http://easts.info/on-line/ proceedings/vol.11/pdf/PP1990_H1.

Mathieson, K. (1991). Predicting User Intentions: Comparing the Technology Acceptance Model with the Theory of Planned Behavior. Inf. Syst. Res. 2 (3), 173-191. doi:10.1287/isre.2.3.173

MIIT (2019). Guidance of Developing Methanol Vehicles in Some Parts of China. Available at: http://www.miit.gov.cn/n1146295/n1652858/n1652930/n3757016/ c6684042/content.html (Accessed Jul 25, 2020).

MIIT (2012). Notification on Methanol Vehicle Pilot Projects. Available at: http://www.ciceia.org.cn/mptdc/news.asp?vid=1224 (Accessed Jul 17, 2020). 
Ministry of Ecology and Environment of China (2019). China Mobile Source Environmental Management Annual Report. Available at: http://www.mee.gov. cn/hjzl/sthjzk/ydyhjgl/201909/P020190905586230826402.pdf (Accessed Jul 17, 2020).

Mohamed, M., Higgins, C., Ferguson, M., and Kanaroglou, P. (2016). Identifying and Characterizing Potential Electric Vehicle Adopters in Canada: A Two-Stage Modelling Approach. Transport Policy 52, 100-112. doi:10.1016/ j.tranpol.2016.07.006

Olah, G. A. (2005). Beyond Oil and Gas: the Methanol Economy. Angew. Chem. Int. Ed. 44 (18), 2636-2639. doi:10.1002/anie.200462121

Park, E., Lim, J., and Cho, Y. (2018). Understanding the Emergence and Social Acceptance of Electric Vehicles as Next-Generation Models for the Automobile Industry. Sustainability 10 (3), 662. doi:10.3390/su10030662

Penerbit, U. M. T. (2015). Determinants of the Intention to Use a Natural Gas Vehicle (NGV) as an Alternative to a Petrol Car: the Case of Malaysia. J. Sustainability Sci. Manag. 10 (1), 36-49.

Petschnig, M., Heidenreich, S., and Spieth, P. (2014). Innovative Alternatives Take Action - Investigating Determinants of Alternative Fuel Vehicle Adoption. Transportation Res. Part A: Pol. Pract. 61, 68-83. doi:10.1016/j.tra.2014.01.001

Pfoser, S., Schauer, O., and Costa, Y. (2018). Acceptance of LNG as an Alternative Fuel: Determinants and Policy Implications. Energy Policy 120, 259-267. doi:10.1016/j.enpol.2018.05.046

Rossiter, J. R. (2002). The C-OAR-SE Procedure for Scale Development in Marketing. Int. J. Res. marketing 19 (4), 305-335. doi:10.1016/S01678116(02)00097-6

She, Z.-Y., Qing Sun, Q., Ma, J.-J., and Xie, B.-C. (2017). What Are the Barriers to Widespread Adoption of Battery Electric Vehicles? A Survey of Public Perception in Tianjin, China. Transport Policy 56, 29-40. doi:10.1016/ j.tranpol.2017.03.001

Shih, C. F., Zhang, T., Li, J., and Bai, C. (2018). Powering the Future with Liquid sunshine. Joule 2 (10), 1925-1949. doi:10.1016/j.joule.2018.08.016

Sovacool, B. K. (2017). Experts, Theories, and Electric Mobility Transitions: Toward an Integrated Conceptual Framework for the Adoption of Electric Vehicles. Energ. Res. Soc. Sci. 27, 78-95. doi:10.1016/ j.erss.2017.02.014

Su, L.-W., Li, X.-R., and Sun, Z.-Y. (2013). The Consumption, Production and Transportation of Methanol in China: A Review. Energy Policy 63, 130-138. doi:10.1016/j.enpol.2013.08.031

Sweeney, J. C., and Soutar, G. N. (2001). Consumer Perceived Value: The Development of a Multiple Item Scale. J. retailing 77 (2), 203-220. doi:10.1016/S0022-4359(01)00041-0

Venkatesh, V., and Bala, H. (2008). Technology Acceptance Model 3 and a Research Agenda on Interventions. Decis. Sci. 39 (2), 273-315. doi:10.1111/ j.1540-5915.2008.00192.x

Venkatesh, V., and Davis, F. D. (2000). A Theoretical Extension of the Technology Acceptance Model: Four Longitudinal Field Studies. Manag. Sci. 46 (2), 186-204. doi:10.1287/mnsc.46.2.186.11926

Venkatesh, V., Morris, M. G., Davis, G. B., and Davis, F. D. (2003). User Acceptance of Information Technology: Toward a Unified View. MIS Q. 27, 425-478. doi:10.2307/30036540

Venkatesh, V., Thong, J. Y., and Xu, X. (2012). Consumer Acceptance and Use of Information Technology: Extending the Unified Theory of Acceptance and Use of Technology. MIS Q. 36 (1), 157-178. doi:10.2307/41410412
Wang, N., Tang, L., and Pan, H. (2018). Analysis of Public Acceptance of Electric Vehicles: An Empirical Study in Shanghai. Technol. Forecast. Soc. Change 126, 284-291. doi:10.1016/j.techfore.2017.09.011

Wang, S., Fan, J., Zhao, D., Yang, S., and Fu, Y. (2016). Predicting Consumers' Intention to Adopt Hybrid Electric Vehicles: Using an Extended Version of the Theory of Planned Behavior Model. Transportation 43 (1), 123-143. doi:10.1007/s11116-014-9567-9

Wang, X., Ge, Y., Liu, L., Peng, Z., Hao, L., Yin, H., Ding, Y., and Wang, J. (2015). Evaluation on Toxic Reduction and Fuel Economy of a Gasoline Direct Injection- (GDI-) Powered Passenger Car Fueled with Methanol-Gasoline Blends with Various Substitution Ratios. Appl. Energ. 157, 134-143. doi:10.1016/j.apenergy.2015.08.023

Will, C., and Schuller, A. (2016). Understanding User Acceptance Factors of Electric Vehicle Smart Charging. Transportation Res. C: Emerging Tech. 71, 198-214. doi:10.1016/j.trc.2016.07.006

Wu, J., Liao, H., Wang, J.-W., and Chen, T. (2019). The Role of Environmental Concern in the Public Acceptance of Autonomous Electric Vehicles: A Survey from China. Transportation Res. F: Traffic Psychol. Behav. 60, 37-46. doi:10.1016/j.trf.2018.09.029

Xu, Y., Zhang, W., Bao, H., Zhang, S., and Xiang, Y. (2019). A SEM-Neural Network Approach to Predict Customers' Intention to Purchase Battery Electric Vehicles in China's Zhejiang Province. Sustainability 11 (11), 3164. doi:10.3390/su11113164

Yao, Y., Chang, Y., Huang, R., Zhang, L., and Masanet, E. (2018). Environmental Implications of the Methanol Economy in China: Well-To-Wheel Comparison of Energy and Environmental Emissions for Different Methanol Fuel Production Pathways. J. Clean. Prod. 172, 1381-1390. doi:10.1016/j.jclepro.2017.10.232

Zhang, K., Guo, H., Yao, G., Li, C., Zhang, Y., and Wang, W. (2018). Modeling Acceptance of Electric Vehicle Sharing Based on Theory of Planned Behavior. Sustainability 10 (12), 4686. doi:10.3390/su10124686

Zhang, L., and Qin, Q. (2018). China's New Energy Vehicle Policies: Evolution, Comparison and Recommendation. Transportation Res. Part A: Pol. Pract. 110, 57-72. doi:10.1016/j.tra.2018.02.012

Zhou, Y., Zhang, H., and Ding, M. (2015). How Public Demonstration Projects Affect the Emergence of New Industries: An Empirical Study of Electric Vehicles in China. Innovation 17 (2), 159-181. doi:10.1080/14479338.2015.1011051

Conflict of Interest: The authors declare that the research was conducted in the absence of any commercial or financial relationships that could be construed as a potential conflict of interest.

Publisher's Note: All claims expressed in this article are solely those of the authors and do not necessarily represent those of their affiliated organizations, or those of the publisher, the editors and the reviewers. Any product that may be evaluated in this article, or claim that may be made by its manufacturer, is not guaranteed or endorsed by the publisher.

Copyright (c) $2021 \mathrm{Li}$, Negnevitsky, Wang, Wang and Hu. This is an open-access article distributed under the terms of the Creative Commons Attribution License (CC $B Y)$. The use, distribution or reproduction in other forums is permitted, provided the original author(s) and the copyright owner(s) are credited and that the original publication in this journal is cited, in accordance with accepted academic practice. No use, distribution or reproduction is permitted which does not comply with these terms. 